\title{
The structure of human attention: Evidence for separate spatial and verbal resource pools
}

\author{
WALTER S. PRITCHARD \\ University of Texas Medical Branch, Galveston, Texas \\ and \\ RICK HENDRICKSON \\ Southeast Missouri State University, Cape Girardeau, Missouri
}

(Joel S. Warm, sponsor)

\begin{abstract}
Recent evidence has suggested that human limited-capacity information-processing resources do not reside in a unitary, undifferentiated pool. Rather, multiple and at least partially independent pools appear to exist. The present investigation addressed this issue. Subjects performed a spatial memory load secondary task in conjunction with either a spatial or a verbal primary task. The two primary tasks were structurally highly similar. Results indicated that performance of the spatial memory load secondary task was significantly poorer when it was paired with the spatial primary task than when it was paired with the verbal primary task. The results are interpreted as indicating the existence of at least partially independent spatial and verbal resource pools.
\end{abstract}

The human brain does not possess an unlimited information-processing capacity. Often the scope of processing must be selectively narrowed to some subset of the total information potentially available, frequently at the expense of losing information outside the attentional focus. This limited information-processing capacity initially was modeled in terms of a unitary pool of finite "mental resources." According to this view, the resources residing in the pool were undifferentiated, that is, could be allocated with equal efficiency to any informationprocessing task regardless of nature (Kahneman, 1973).

The notion of a single, general-purpose resource pool has recently been challenged by the idea that multiple, specialized resource pools may exist (Navon \& Gopher, 1979; Wickens, 1980). According to this multipleresource point of view, the resources from a given pool are specialized in nature. They can be applied with maximal efficiency only to tasks of a certain "resource composition," and are at best less efficient when applied to other types of tasks. For example, a growing body of evidence has converged on the conclusion that response selec-

Preparation of this manuscript was supported in part by a grant from the Moody Foundation. A preliminary version of this paper was presented at the First Mid-Central Ergonomics/Human Factors Conference, Cincinnati, OH, April, 1984. The authors wish to thank Ernest S. Barratt for his helpful comments. Address reprint requests to Walter S. Pritchard, Psychophysiology Laboratory, Department of Psychiatry and Behavioral Sciences, D-43, University of Texas Medical Branch, Galveston, Texas 77550 . tion draws resources from a different pool from that of perceptual processing (Gopher, Brickner, \& Navon, 1982; Isreal, Chesney, Wickens, \& Donchin, 1980; Isreal, Wickens, Chesney, \& Donchin, 1980; Wickens, Kramer, Vanasse, \& Donchin, 1983).

Multiple-resource theory has also focused on the possibility that spatial information-processing tasks may draw resources from a different pool from that of verbal information-processing tasks. Such a dichotomy of course parallels the lateralized specialization of the human cerebrum. Studies investigating this possibility have employed versions of the ubiquitous dual-task paradigm. For example, it was found that performance of a "lefthemisphere"' task, such as speech shadowing, did not deteriorate when subjects simultaneously performed "righthemisphere" tasks, such as viewing complex visual scenes or sight-reading music (Allport, Antonis, \& Reynolds, 1972).

More recent investigations (Friedman \& Polson, 1981; Friedman, Polson, Dafoe, \& Gaskill, 1982; Hellige, Cox, \& Litvac, 1979) have added a clever innovation to the basic dual-task paradigm. In conjunction with verbal and/or spatial memory load secondary tasks, the same primary task was presented to either the left or the right visual field. The goal of this manipulation was to lateralize sensory input to a single cerebral hemisphere at a time, and hence to vary the resource composition of the primary task along a spatial/verbal dimension. The assumption was made that, since structural aspects of the task remained constant, its difficulty would not vary as a function of 
lateralized presentation. However, other research (Sergent, 1982) has indicated that the two cerebral hemispheres may not have equivalent spatial-frequency sensitivities. Thus, converging evidence from experiments that vary resource composition by a means other than varying visual field of presentation would seem to be in order.

The notion of separate spatial and verbal resource pools directly relates to previous research investigating the possible existence of separate visuospatial and verbal/acoustic working memory (WM) systems (Atwood, 1971; Brooks, 1968; Kroll, 1972; Kroll \& Kellicutt, 1972; Kroll, Parks, Parkinson, Bieber, \& Johnson, 1970; Parkinson, 1972; Parkinson, Parks, \& Kroll, 1971; Salzberg, Parks, Kroll, \& Parkinson, 1971; Segal \& Fusella, 1970; Shulman, 1972). The relation is direct because WM is currently conceptualized as being synonymous with the employment of limited-capacity, attentional resources for information storage and manipulation in a "currently activated" buffer, or "workbench" (see Klatzky, 1980).

These WM studies employed either dual-task paradigms or conceptually similar paradigms in which a subsequently presented shadowing task retroactively interfered with the retention of items in WM. However, an unambiguous interpretation of the dual-task WM research in terms of separate spatial versus verbal resource pools is problematical. In these studies, the enhanced interference obtained may have been "structural" in nature (see Kahneman, 1973). That is, dual-task performance decrements may have been seen not because the two tasks were competing for the same central pool of resources, but rather because they occupied the same peripheral mechanisms of perception or response. For example, it has been demonstrated that visual WM tasks tend to produce a dramatic decrease in eye movements (Hiscock \& Bergstrom, 1981; Weiner \& Erlichman, 1976). This by itself would degrade performance more on a visual secondary task requiring eye movements than on an auditory secondary task not requiring eye movements. The present investigation sought to gather evidence of separate spatial and verbal resource pools using a paradigm that did not confound attentional and structural interference and that also varied resource composition by a method other than varying visual field of presentation.

Subjects performed either a spatial or a verbal primary task while concurrently performing a spatial memory load secondary task. This particular secondary task was chosen because previous research had clearly indicated that WM load tasks produced resource-limited rather than structural interference, regardless of the nature of the primary task with which they were paired (see Wickens, 1980). The spatial and verbal primary tasks employed were structurally quite similar: They had similar stimulus properties, did not require differential amounts of eye movement, and had identical response requirements.

Single- and multiple-resource points of view generate different predictions regarding the outcome to be expected in such a paradigm. A single-resource viewpoint would predict equal single-to-dual-task performance decrements for both primary tasks, along with equal dual-task performance of the spatial memory load secondary task. A separate spatial versus verbal resource viewpoint, however, would predict a greater dual-task performance decrement for the spatial primary task than for the verbal primary task and/or poorer dual task performance of the spatial memory load secondary task when it is paired with the spatial primary task.

\section{METHOD}

Thirty-four subjects (18 females) voluntarily participated in the experiment in exchange for class credit in an undergraduate psychology course. Stimuli were presented in a three-channel tachistoscope. On each trial, the subjects viewed the following stimulus sequence (see Figure 1 for a schematic): Initially, a random $5 \times 5$ histoform was presented for $1 \mathrm{sec}$. This was followed immediately by a pair of either verbal or spatial stimuli presented for $1.5 \mathrm{sec}$. The verbal pairs consisted of two common nouns arrayed one immediately above the other. Each noun was an exemplar drawn from one of three categories (birds, trees, or articles of clothing), with four exemplars per category. On half of the trials, the pairs were drawn from the same category; on the other half of the trials, the pairs were drawn from different categories. The spatial pairs consisted of two strings of three typewriter "nonsense" characters arrayed one immediately above the other. The individual nonsense characters (@,\#,\$,\%,\&, or *) were comparable in size to the individual letters used to compose the verbal stimuli. The nonsense characters were spaced such that the horizontal length of the nonsense strings corresponded to the average horizontal length of the words. On half the trials, the spatial pairs were physically identical; on half the trials, the spatial pairs differed by two characters. The pair stimuli were immediately followed by the final stimulus in the sequence, a second random histoform presented for $1 \mathrm{sec}$. This second histoform was either identical to (half the trials) or different from (half the trials) the first random histoform presented at the beginning of the sequence.

All stimuli were black ink on white index cards. The white portion of the stimulus cards had a luminance of $27.0 \mathrm{~cd} / \mathrm{m}^{2}$. The histoform stimuli were generated randomly within a $5 \times 5$ matrix subtending a visual angle of $0.95^{\circ}$ to form a population of 12 . The pair stimuli were typed in Pica, with each character vertically subtending a visual angle of $0.13^{\circ}$. The exemplars constituting the verbal pair stimuli were: birds-robin, lark, dove, finch; trees-maple, pine, oak, birch; and articles of clothing-dress, shirt, coat, shoe. All relevant stimulus conditions (same/different order for both the pair and histoform stimuli, selection of individual words/nonsense strings for the pair stimuli, selection of individual histoforms for the histoform stimuli) were randomized.

The subjects positioned one hand on each of two response buttons. The buttons were interfaced with electric clocks that kept track of the subjects' reaction times (RTs) in the various experimental conditions. The subjects were told that the button under the dominant hand signified "same" and that the button under their nondominant hand signified "different." They initially were instructed to ignore the pair stimuli and to respond "same" or "different" to the second histoform as quickly as they could while still maintaining accuracy, depending upon whether or not it physically matched the first histoform. After 10 such histoformonly practice trails, the subjects were instructed to ignore the histoforms and respond "same" or "different" to the pair stimuli. They were then given 18 such pair-only practice trials.

After completing these single-task practice conditions, the subjects were instructed to respond appropriately on each trial to both the pair stimuli and the second histoform, and to consider the two tasks to be of equal importance. The Subjects were given 46 of these dual-task trials. To be successful in this condition, the subjects had to maintain a representation of the first histoform in WM while responding to the pairs.

Following the dual-task condition, the subjects were given an additional 28 pair-only trials. This was done in order to establish singletask baselines against which performance of the pair tasks in the dual- 


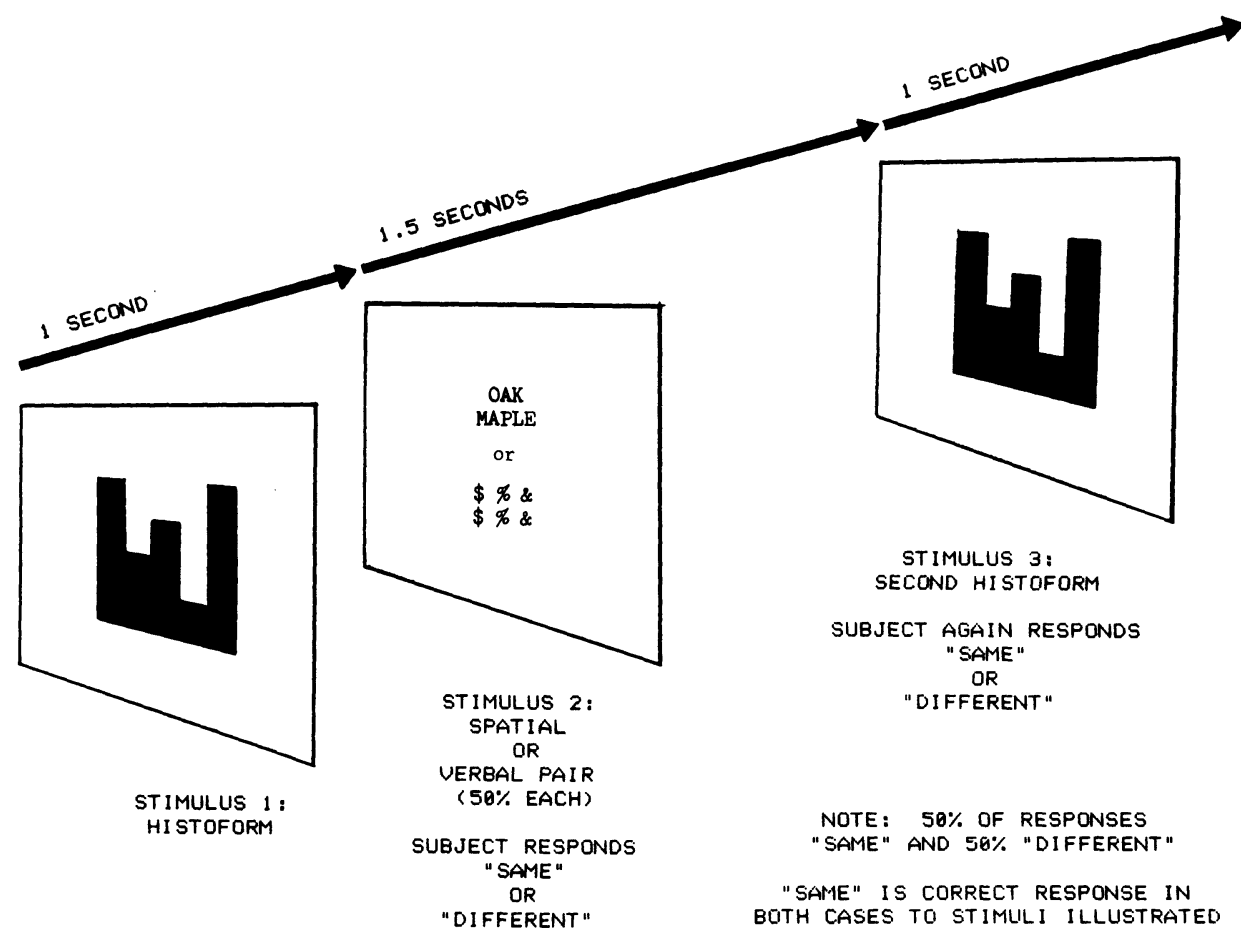

Figure 1. A temporal schematic of the sequence of stimuli viewed by subjects on each trial.

task condition could be compared. The necessity of giving their best performance on each trial of this baseline condition was emphasized strongly to each subject.

\section{RESULTS}

Analysis of subjects' responses to the pairs in the dualtask condition versus those in the baseline condition indicated that dual-task interference was equal for the spatial and verbal pair tasks. For each subject, spatial and verbal interference scores were computed by subtracting the average RT obtained in the single-task baseline condition (pair task by itself) from the average RT obtained in the dual-task condition (pair task combined with the spatial memory load secondary task). Average spatial and verbal interference scores were then computed across subjects. For the spatial pairs, the average interference score was $184 \mathrm{msec}$; for the verbal pairs, the average interference score was $179 \mathrm{msec}$. Although both of these differed significantly from zero [for the spatial pairs, $\mathrm{t}(33)=8.21$, $\mathrm{p}<.001$; for the verbal pairs, $\mathrm{t}(33)=7.80, \mathrm{p}<.001]$, they did not differ significantly from each other, $[\mathrm{t}(32)$ $=0.18$, n.s.]. RTs to the pairs in the dual-task condition were not influenced by a speed-accuracy tradeoff $^{1}[\mathrm{r}=$ $-0.030, \mathrm{t}(66)=-0.17$, n.s.].

Analysis of subjects' responses to the second histoform in the dual-task condition indicated that the average RT was significantly slower if a histoform stimulus had been preceded by a spatial pair than if it had been preceded by a verbal pair [846 msec vs. $811 \mathrm{msec} ; \mathrm{t}(32)=3.15$, $\mathrm{p}<.01]$.

\section{DISCUSSION}

The results of the present investigation indicated that, although singleto-dual-task performance decrements were equivalent for both the spatial and verbal pair tasks, the speed of response to the second histoform was significantly slower if it had been preceded by a spatial pair than if it had been preceded by a verbal pair. This pattern could have been expected if the spatial pair task had been intrinsically more difficult than the verbal pair task. This would have forced subjects to draw more resources from what could in fact be a unitary pool of resources when responding to the spatial pairs. Thus, in order to keep performance on the spatial and verbal pair tasks equal in the dual-task condition, performance on any type of demanding secondary task would be poorer when it was paired with the spatial pair task, since fewer resources would be left over to perform the secondary task.

However, a comparison of single-task performances clearly indicates that, if anything, the spatial pair task may have been intrinsically easier than the verbal pair task. For single-task baselines obtained after the dual-task condition, the average RT to the spatial pairs was faster than the average RT to the verbal pairs $[990 \mathrm{msec} v s .1,036 \mathrm{msec} ; \mathrm{t}(32)$ $=2.18, \mathrm{p}<.05]$. These RTs did show a tendency toward a slight speedaccuracy tradeoff $[\mathrm{r}=-.025, \mathrm{t}(66)=1.46, \mathrm{p}<.15]$. A similar pattern was seen for the RTs obtained during single-task practice prior to the dual-task condition [an average of $1,198 \mathrm{msec}$ for the spatial pairs vs. $1,259 \mathrm{msec}$ for the verbal pairs; $\mathrm{t}(32)=1.82, \mathrm{p}<.10$ ]. These RTs did not display any trend toward a speed-accuracy tradeoff $[\mathrm{r}=$ $0.006, \mathrm{t}(66)=0.05$, n.s.].

The most likely explanation of the experimental results obtained is that at least partially independent spatial and verbal resource pools exist. The subjects apparently sought to maintain equivalent performances on the spatial and verbal primary tasks in the dual-task condition. The fact that a $t$ ratio of 0.18 represents a marginally significant suppression of error variance between the two means $(p>.90)$ supports this notion. It appears that this could be done, however, only at the expense of draining more resources from WM maintenance when a spatial pair was presented than when a verbal pair was presented. This would result in a more degraded WM representation of the first histoform following a spatial pair that in turn took longer to compare with the second histo- 
form when it was presented. This could have occurred only if at least partially independent spatial and verbal resource pools subserved WM function. The results of the present study thus converge with previous results upon the conclusion that human attentional resoures are not unitary in nature. At least partially independent pools appear to exist along at least two dichotomies (perceptual processing vs. response selection and spatial vs. verbal).

\section{REFERENCES}

Allport, D. A., Antonis, B., \& Reynolds, P. (1972). On the division of attention: A disproof of the single channel hypothesis. Quarterly Journal of Experimental Psychology, 24, 225-235.

ATwood, G. A. (1971). An experimental study of visual imagination and memory. Cognitive Psychology, 2, 290-299.

BRooKs, L. R. (1968). Spatial and verbal components of the act of recall. Canadian Journal of Psychology, 22, 349-368.

Friedman, A., \& Polson, M. C. (1981). Hemispheres as independent resource systems: Limited-capacity processing and cerebral specialization. Journal of Experimental Psychology: Human Perception and Performance, 7, 1031-1058.

Friedman, A., Polson, M. C., Dafoe, C. G., \& Gaskill, S. J. (1982). Dividing attention within and between hemispheres: Testing a multiple resources approach to limited capacity information processing. Journal of Experimental Psychology: Human Perception and Performance, 8, 625-650.

Gopher, D., BrickNer, M., \& NAVON, D. (1982). Different difficulty manipulations interact differently with task emphasis: Evidence for multiple resources. Journal of Experimental Psychology: Human Perception and Performance, 8, 146-157.

Hellige, J. B., Cox, P. J., \& LiTVAC, L. (1979). Information processing in the cerebral hemispheres: Selective hemispheric activation and capacity limitations. Journal of Experimental Psychology: General, 108, 251-279.

Hiscock, M., \& Bergstrom, K. J. (1981). Ocular motility as an indicator of verbal and visuospatial processing. Memory \& Cognition, 9, 332-338.

Isreal, J. B., Chesney, G. L., Wickens, C. D., \& Donchin, E. (1980). P300 and tracking difficulty: Evidence for multiple resources in dual-task performance. Psychophysiology, 17, 259-273.

Isreal, J. B., Wickens, C. D., Chesney, G. L., \& Donchin, E. (1980). The event-related potential as an index of display monitoring workload. Human Factors, 22, 211-224.

Kahneman, D. (1973). Attention and Effort. Englewood Cliffs, NJ: Prentice Hall.

KlatZky, R. L. (1980). Human Memory, 2nd. ed. San Francisco: Freeman.

Kroll, N. E. A. (1972). Short-term memory and the nature of interference from concurrent shadowing. Quarterly Journal of Experimental Psychology, 24, 414-419.

Kroll, N. E. A., \& Kellicutt, M. H. (1972). Short-term recall as a function of covert rehearsal and of intervening task. Journal of Verbal Learning and Verbal Behavior, 11, 196-204.

Kroll, N. E. A., Parks, T., Parkinson, S. R., Bieber, S. L., \& JohnSON, A. L. (1970). Short-term memory while shadowing: Recall of visually and aurally presented letters. Journal of Experimental Psychology, 85, 220-224.

Navon, D., \& Gopher, D. (1979). On the economy of the humanprocessing system. Psychological Review, 86, 214-255.

PaChella, R. G. (1974). The interpretation of reaction time in information processing research. In B. H. Kantowitz (Ed.), Human information processing: Tutorials in performance and cognition. Hillsdale, $\mathrm{NJ}$ : Erlbaum.

Parkinson, S. R. (1972). Short-term memory while shadowing: Multiple-item recall of visually and of aurally presented letters. Journal of Experimental Psychology, 92, 256-265.

Parkinson, S. R., Parks, T. E., \& Kroll, N. E. A. (1971). Visual and auditory short-term memory: Effects of phonemically similar auditory shadow material during the retention interval. Journal of Experimental Psychology, 87, 274-280.

Salzberg, P. M., Parks, T. E., Kroll, N. E. A., \& Parkinson, S. R. (1971). Retroactive effects of phonemic similarity on short-term recall of visual and auditory stimuli. Journal of Experimental Psychology, 91, 43-46.

SEgAL, S. J., \& FuSELla, V. (1970). Influence of imaged pictures and sounds on detection of visual and auditory signals. Journal of Experimental Psychology, 83, 458-464.

SERGENT, J. (1982). The cerebral balance of power: Confrontation or cooperation? Journal of Experimental Psychology: Human Perception and Performance, 8, 253-272.

ShulmaN, H. G. (1972). Semantic confusion errors in short-term memory. Journal of Verbal Learning and Verbal Behavior, 11, 221-227.

Weiner, S. L., \& ERlichman, H. (1976). Ocular motility and cognitive process. Cognition, 4, 31-43.

WiCKENS, C. D. (1980). The structure of attentional resources. In R. S. Nickerson (Ed.), Attention and performance VIII. Hillsdale, NJ: Erlbaum.

Wickens, C., Kramer, A., Vanasse, L., \& Donchin, E. (1983). Performance of concurrent tasks: A psychophysiological analysis of the reciprocity of information processing resources. Science, 221, 1080-1082.

\section{NOTE}

1. In all cases, the possibility of a speed-accuracy tradeoff was assessed by computing the Pearson product-moment correlation coefficient ( $r$ ) between RT and the percentage of RT errors (see Pachella, 1974).

(Manuscript received for publication March 4, 1985.) 